\title{
Article \\ Experimental and Simulated Investigation of Lubrication Characteristics of a Water-Lubricated Bearing in a Single-Screw Compressor
}

\author{
Jia Xie, Chengyu Peng, Wenshan Zhang, Cun Zhao * and Quanke Feng
}

Citation: Xie, J.; Peng, C.; Zhang, W.; Zhao, C.; Feng, Q. Experimental and Simulated Investigation of Lubrication Characteristics of a Water-Lubricated Bearing in a Single-Screw Compressor. Appl. Sci. 2021, 11, 9920. https://doi.org/ 10.3390/app11219920

Academic Editor: Homer Rahnejat

Received: 15 September 2021

Accepted: 21 October 2021

Published: 23 October 2021

Publisher's Note: MDPI stays neutral with regard to jurisdictional claims in published maps and institutional affiliations.

Copyright: (c) 2021 by the authors. Licensee MDPI, Basel, Switzerland. This article is an open access article distributed under the terms and conditions of the Creative Commons Attribution (CC BY) license (https:// creativecommons.org/licenses/by/ $4.0 /)$.
School of Energy and Power, Xi'an Jiaotong University, Xi'an 710049, China; jiajiawa_1990@stu.xjtu.edu.cn (J.X.); pcy1993@stu.xjtu.edu.cn (C.P.); wenshan.1990@stu.xjtu.edu.cn (W.Z.); qkfeng@mail.xjtu.edu.cn (Q.F.)

* Correspondence: zhaocun@mail.xjtu.edu.cn

\begin{abstract}
Water-lubricated single-screw compressors (WSSCs) have developed rapidly in recent years because they can supply oil-free compressed air at considerably low costs. However, a major technical obstacle is that the conventional bearing arrangement of a star wheel shaft is prone to wear failure, which makes it difficult for WSSCs to run properly for long periods of time. To solve this problem, a star wheel thrust bearing with new liquid groove was proposed in this paper. Pulsating forces (i.e., bearing forces) acting on a star wheel shaft by compressing air were calculated through the dynamic analysis of the star wheel shaft system. A mathematical model of hydraulic water films in the bearing sliding clearance was established to describe the influence of water injection pressure on water film pressure distribution and its bearing capacity. Lubrication characteristics were compared between two types of hydrostatic thrust bearings (HTBs) with different grooves to illustrate that the new structure is more suitable for WSSCs. The reasonability of the proposed model and simulation results were verified using an axial thrust bearing test rig developed by the authors. In addition, variation parameters of hydrostatic film thickness between the sliding surfaces of the star wheel axial thrust bearing were measured. The results show that the instability of the water film thickness and axial vibration of the star wheel were suppressed, thereby avoiding the contact of solid materials between the end face of the axial thrust bearing. This study provides a structural optimization pattern of star wheel axial thrust bearings used in water-lubricated single-screw compressors.
\end{abstract}

Keywords: water-lubricated single-screw compressor (WSSC); hydrostatic thrust bearing (HTB); bearing performance; working stability

\section{Introduction}

Single-screw compressors can offer reliable and efficient compression services in several industrial fields. In recent years, water-lubricated single-screw compressors (WSSCs)have increasingly prevailed in the fields of food, pharmaceuticals, petrochemical industry, and new energy owing to their advantages, such as their energy consumption, their oil-free nature in discharging air, lower manufacturing cost, and relatively lower maintenance cost compared to other types of compressors [1-3].The WSSC structure is shown in Figure 1; the WSSC utilizes one screw rotor to mesh with two star wheels which are located on separated shafts mounted at right angles to the main rotor axis. As the screw rotor rotates, spaces form between the screw groove, the star wheel and the casing, and then gas from suction port flows into fill this space, which increases until the particular screw groove moves out of mesh with the star wheel. Continued rotation brings the screw groove full of gas into mesh with the next star wheel on the other side of the rotor; the trapped volume decreases, and the gas pressure increases as the star wheel sweeps along the screw groove. The final part of the process is the discharge phase, where all the gas is swept out of the screw groove by the star wheel. With the proposal and implementation of a multi-column envelope meshing pair profile [4], breakthroughs have been achieved on 
the rapid wear issue of star wheel tooth surfaces in WSSCs. On the basis of the adaption of a new meshing profile, WSSCs with large displacement and a high compression ratio have been developed in numerous Chinese companies. However, rapid wear and scuff often occur in their star wheel's thrust bearings due to the increase in and fluctuation of forces, which has become a main barrier to the development of WSSCs.

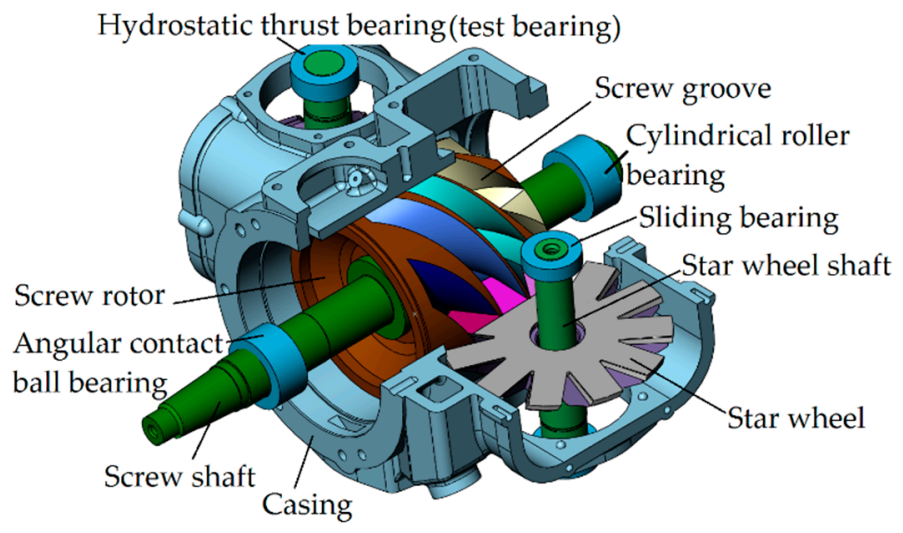

Figure 1. Structure of a single-screw compressor.

At present, two types of axis thrust bearings are used in WSSCs. The first type is rolling bearings lubricated with grease, which should be tightly sealed and relatively difficult for frictional heat to dissipate. This condition consequently increases the compressor manufacturing cost and operational failure of the rolling bearings [5,6]. Moreover, a rolling bearing appears to encounter numerous failures when radium and axis pulsating forces act simultaneously. The other type is water-lubricated thrust bearings composed of a high hardness shaft and graphite sleeve, in which no hydraulic film is formed. Axial forces acting on the star wheel shaft make solid materials that are contacted directly, resulting in the graphite shaft sleeve wearing out fast. Water lubricated bearings are apt for use in WSSCs owing to the small meshing forces and minimal friction between their star wheel and screw tooth. In WSSCs, the air-water mixture is discharged from the discharge port at the end of the compression process and enters the gas-water separator thereafter for separation. After cooling in a cooler, lubricating water is injected into the compression chamber. Given that pressure in the gas-water separator is the same as the discharge pressure, the pressure difference between the exhaust pressure and suction pressure is often the injection pressure difference before and after the nozzle. WSSCs can automatically supply high-pressure water that can be injected into the hydrostatic thrust bearings of compressors to balance the axial forces and reduce the contact wear between two surfaces.

With the continuous development of the application of water-lubricated bearings in machinery, research has mainly focused on their reliability and bearing performance. Qiu et al. analyzed the influence of the guide bearing load of large vertical pumps on the structure, design, manufacturing construction and installation errors of pump unit and assembly [7]. They established the probabilistic load theory of guide bearing for the first time and studied the modeling method and characteristics of bearing probability load. He et al. studied the lubrication characteristics of the water-lubricated thrust bearing of submersible pumps through simulation and experiment [8]. Scholars have studied the performance of the water-lubricated thrust bearing in a variety of machines; however, there are few studies on HTBs used in WSSCs. Heidrich and Li both proposed to use a water-lubricated sliding bearing in WSSCs, but they did not give a detailed introduction $[9,10]$. Zhang analyzed the thermal deformation mechanism of the meshing pairs in single-screw compressors and proposed that the thermal deformation could be controlled by adjusting the bearing position [11]. The bearing performance plays an important role in the operation of WSSCs, especially the HTB of the star wheel shaft. The performance of water-lubricated thrust bearings is investigated by various methods. M. Rohmer et al. assembled a water-lubricated test rig to measure the performance of hydrostatic thrust bearings [12]. Wang et al. simulated 
the influence of structure and working parameters, such as water film thickness, water injection hole diameter, and speed, on the bearing capacity of hydrostatic bearings [13]. Liu et al. calculated the pressure distribution of water film in a water-lubricated thrust bearing using MATLAB and studied the influence of operating and bearing geometry parameters on a bearing's main lubricating performance [14]. Andres et al. investigated the relationships between the main parameters of water-lubricated HTBs, such as bearing clearance, water injection pressure, water film thickness and bearing capacity, by conducting experiments [15]. Zhang et al. analyzed the bearing capacity of the HTB after the optimization design, then verified the simulation results by experiment [16].The effect of the groove shape on the bearing performance was also studied in the relevant literature. Sternlicht and Elwell, Rowe, Chen and Ding derived formulas for the lubricant flow rate and load capacity of a single circular groove HTB and annular multi-recess HTBs and verified their accuracies against experimental results [17-20]. Tian analyzed and compared the bearing capacity of the hydrostatic with a circular and annular groove and deduced the calculation method of the dynamic characteristics [21].

In summary, the bearing performance of various thrust bearings and their applications have been studied globally. However, research on their working stability under a large pulsating force has rarely been conducted. Given that the forces of a star wheel acted on by compressed air pulsate significantly with the pressure of compressed air, the following question should be answered: would this pulsation make the rotating ring of a bearing to move up and down in the axial direction and destroy the star wheel piece? Therefore, one of the major problems in the current study is the question of how to avoid large changes in water film thickness and large axial displacement of the star wheel in a compressor.

For star wheel bearings, it is necessary to consume less water while maintaining its stability because the liquid supply of the single-screw compressor is limited. To bring out frictional heat in an HTB via water film flow and increase the distance of water flowing in an HTB, an annular liquid groove crossing with numerous short channels was arranged on the surface of a studied HTB, as shown in Figure 2a. Liquid pressure, $\mathrm{p}_{\mathrm{r}}$, in the groove on the sliding surface of an HTB is directly proportional to the compressor discharge pressure. Moreover, pressure on its inner and outer edges is lower than the compressor suction pressure. However, an annular water groove is often arranged on a conventional HTB surface, as shown in Figure 2b [22]. Evidently, frictional heat and wear particles on the sliding surface of an HTB can hardly be discharged out of the sliding surface. Additionally, a significantly short distance between the groove and outer/inner edges will leak a large volume of injected water. Compared with traditional HTBs with annular grooves, the proposed HTB's unique advantage is that injected water can rapidly drive all frictional heat and particles out of it. Moreover, a large water flow distance in the clearance of a bearing will increase the stability of the water film.

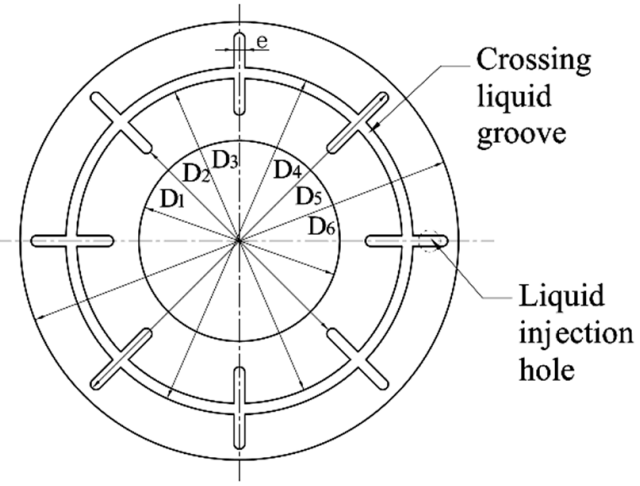

(a)

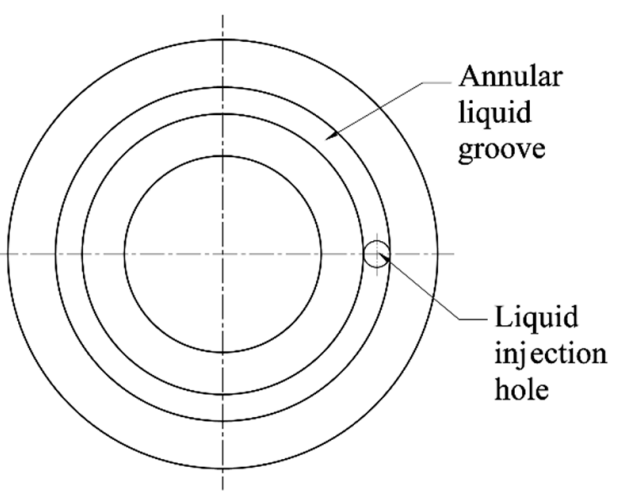

(b)

Figure 2. Structure of HTB: (a) HTB with crossing groove; (b) HTB with annular groove. 
This study uses the increasing application background of WSSCs as a basis on which to conduct working behavior research regarding axial thrust bearings and the quantitative relations of water film thickness to star wheel load, water injection pressure, and the structure of HTBs in WSSCs. The workflow is shown in Figure 3.

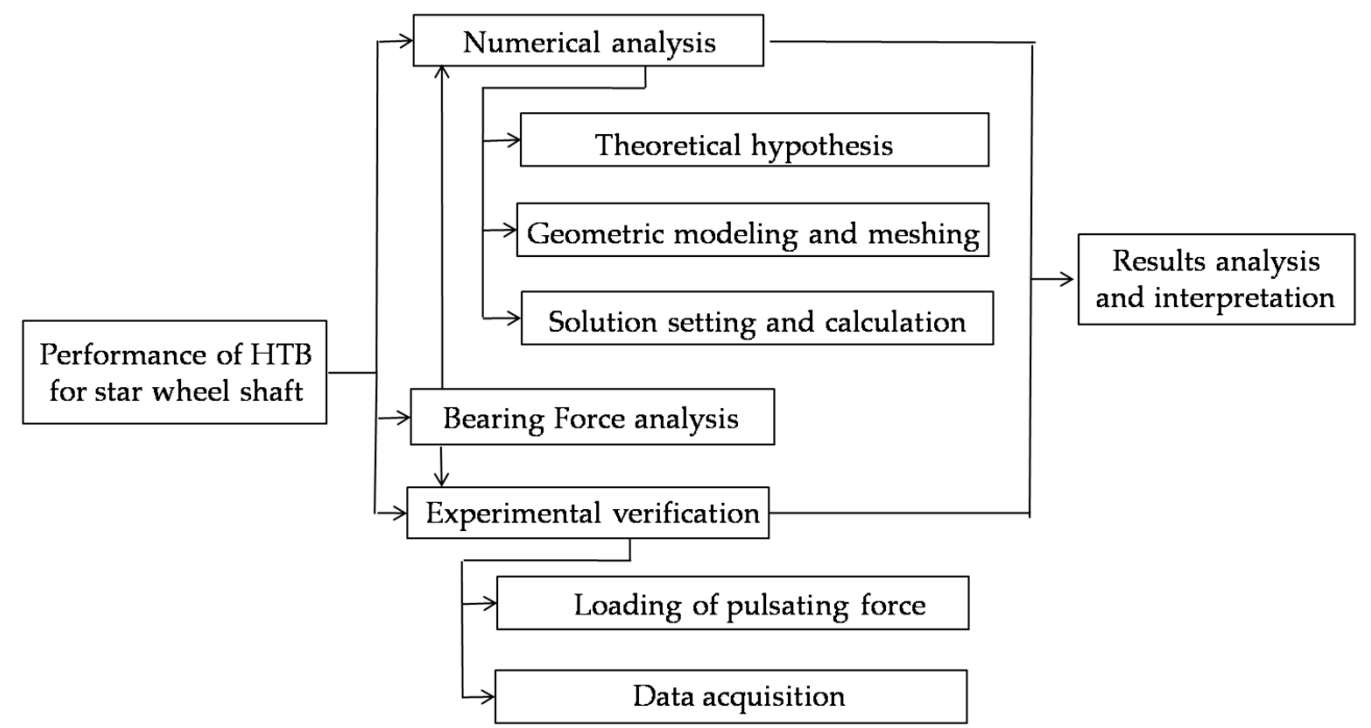

Figure 3. Workflow of the methodology.

\section{Methodology}

2.1. Force Analysis and Parameters of the HTB

2.1.1. Determination of Forces Acting on a Star Wheel

The HTB force used for the star wheel shaft is related to the force of the star wheel. Thus, the force analysis of the star wheel is also the focus of the research on an HTB's working characteristics.

Forces acting on a star wheel mainly come from the action of gas pressure in the cylinder and constricting forces exerted by bearings on them. Illustrations of the acting forces and torques are shown in Figure 4.

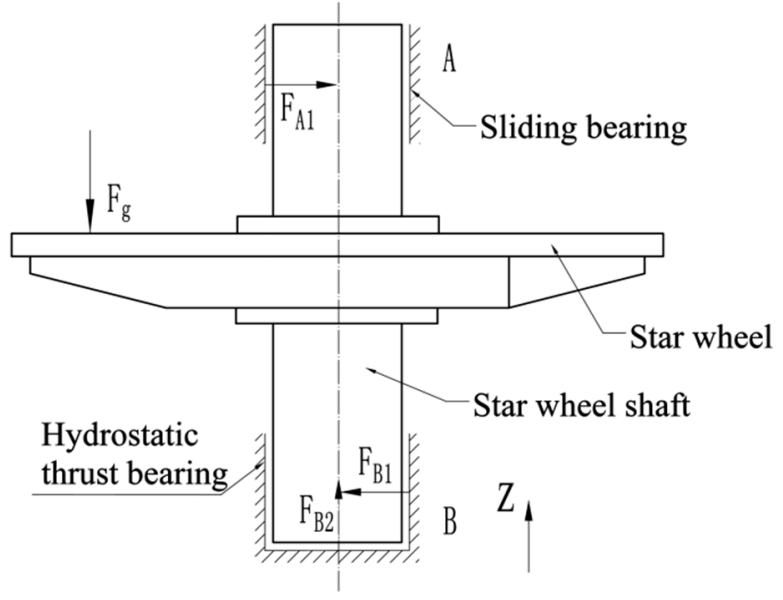

Figure 4. Illustrations of forces acting on a star wheel shaft.

As shown in the figure, the HTB mainly bears the gas force, $\mathrm{F}_{\mathrm{g}}$. According to the working principle of single-screw compressors, gas pressure acting on a star wheel tooth surface often varies with star wheel rotation angle, $\alpha$. This situation also causes the resultant force, $\mathrm{F}_{\mathrm{g}}$, from the gas pressure to change. 
The variable force acting on a star wheel can be calculated using the following equation and relationship:

Gas force, $F_{i g}$, of the $i$ th star wheel tooth meshed into the screw groove is calculated as follows:

$$
F_{i g}(\alpha)=p_{i}(\alpha) A_{i}(\alpha)
$$

Gas pressure, $p_{i}(\alpha)$, acting on the $i$ th star wheel tooth meshing with the screw groove can be calculated using the formulas in the literature [23].The area, $A_{i}(\alpha)$, of the $i$ th star wheel tooth end face closed in the screw groove can be expressed as follows:

$$
A_{i}(\alpha)=\left\{\begin{array}{l}
\int_{-\frac{b}{2}}^{\frac{b}{2}}\left(\sqrt{R_{s w}^{2}-\eta^{2}}-\eta \tan \alpha-\frac{A-R_{s r}}{\cos \alpha}\right) d \eta \alpha_{i n} \leq \alpha \leq \alpha_{o 1} \\
\int_{-\frac{b}{2}}^{R_{s w} \sin \left(\alpha_{o u t}-\alpha\right)}\left(\sqrt{R_{s w}^{2}-\eta^{2}}-\eta \tan \alpha-\frac{A-R_{s r}}{\cos \alpha}\right) d \eta \alpha_{o 1}<\alpha \leq \alpha_{o 2}
\end{array}\right.
$$

where $b$ is the tooth width of the star wheel, $R_{s w}$ is the radium of the star wheel, $d \eta$ is an area element parallel to the tooth centerline on the tooth surface of the star wheel, $\eta$ is the distance between the area element and the tooth centerline, $A$ is the center distance of the screw rotor and star wheel, $R_{s r}$ is the radium of the star wheel, $\alpha_{i n}$ is the star wheel rotation angle at the end of suction, $\alpha_{o 1}$ is the star wheel rotation angle when the star wheel tooth begins to drop off the screw groove, $\alpha_{\text {out }}$ is the star wheel rotation angle when the center of the star wheel begins to drop off the screw groove, and $\alpha_{o 2}$ is the star wheel rotation angle at the end of discharge.

Thus, the resultant force that acts on the star wheel teeth engaging with their screw grooves can be obtained as follows:

$$
F_{g}(\alpha)=\sum_{i=1}^{3} F_{i g}(\alpha)
$$

This resultant force will be the key parameter to determine the water film thickness. On the basis of the preceding description, this study developed a WSSC prototype. The related technique parameters of the prototype are presented in Table 1.

Table 1. Related technique parameters of a WSSC prototype.

\begin{tabular}{cc}
\hline Parameter & Value \\
\hline Diameter of the screw rotor $/ \mathrm{d}_{1}$ & $310 \mathrm{~mm}$ \\
Diameter of the star wheel/d & $310 \mathrm{~mm}$ \\
Center distance/A & $248 \mathrm{~mm}$ \\
Tooth width of the star wheel/b & $49 \mathrm{~mm}$ \\
Rotational speed $/ \mathrm{n}$ & $2970 \mathrm{r} / \mathrm{min}$ \\
Theoretical displacement/ $\mathrm{Q}_{\mathrm{v}}$ & $30 \mathrm{~m}^{3} / \mathrm{min}$ \\
\hline
\end{tabular}

Under a common discharge pressure of $0.5,0.8$ and $1.2 \mathrm{MPa}$, the variation of the resultant force, $F_{g}$, with the rotation angle of the star wheel shaft is shown in Figure 5.

It is shown that the minimum value of gas force, $F_{g m i n}$, is $1203 \mathrm{~N}$, and the maximum value of gas force, $F_{g m a x}$, is $2777 \mathrm{~N}$. This largely fluctuating force, $F_{g}$, will act on the HTB of the star wheel shaft and change the water film thickness between the two sliding surfaces. In general, the screw rotor of a single-screw compressor has six screw grooves. Each elementary volume will complete two gas transmission processes during every rotation of the screw rotor. Therefore, the resultant force, $F_{g}$, has six periods of variation for each rotation of the screw rotor. 


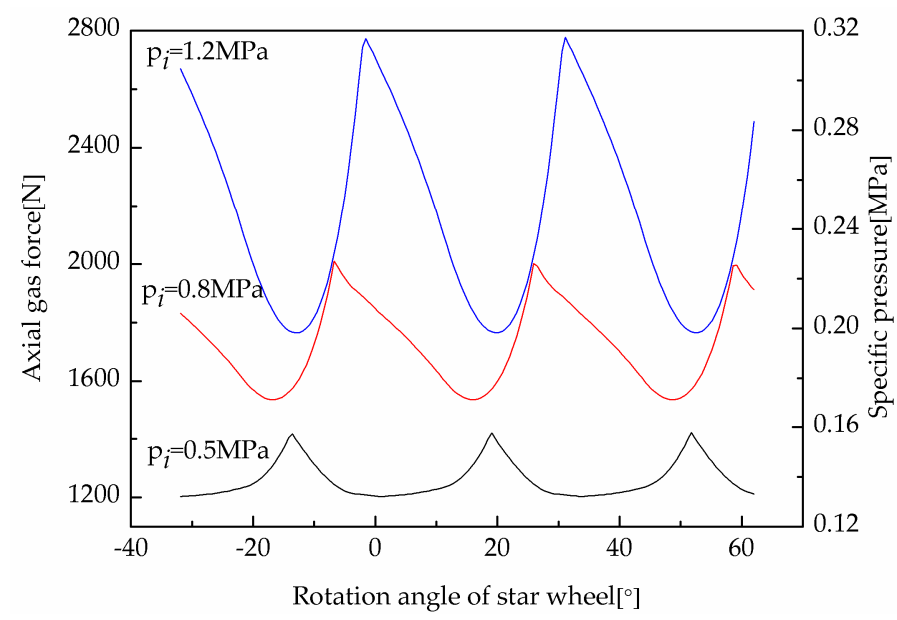

Figure 5. Variation of gas force on star wheel with rotation angle of star wheel.

\subsubsection{Parameters of the Star Wheel HTB}

As shown in Figure $2 \mathrm{a}, \mathrm{D}_{1}$ and $\mathrm{D}_{6}$ are the internal diameter and external diameter of the bearing, respectively. The width of the radial groove is equal to that of the annular part, and the length is about 0.4 times as big as the difference between the internal and external diameters of the bearing. The structural dimensions of the HTB used for the star wheel shaft not only meets the requirements of the use of the star wheel shaft, but also needs to consider the size of the installation space. Parameters of the HTB applicable to the prototype shown in Table 1 are shown in Table 2.

Table 2. Parameters of the HTB for the WSSC prototype.

\begin{tabular}{cc}
\hline Parameter & Value \\
\hline Internal diameter of the HTB $/ \mathrm{D}_{1}$ & $55 \mathrm{~mm}$ \\
Internal diameter of the radial groove $/ \mathrm{D}_{2}$ & $72 \mathrm{~mm}$ \\
Internal diameter of the annular groove $/ \mathrm{D}_{3}$ & $89 \mathrm{~mm}$ \\
External diameter of the annular groove $/ \mathrm{D}_{4}$ & $95 \mathrm{~mm}$ \\
External diameter of the radial groove $/ \mathrm{D}_{5}$ & $111 \mathrm{~mm}$ \\
External diameter of the HTB/D & $120 \mathrm{~mm}$ \\
Width of the groove/e & $3 \mathrm{~mm}$ \\
\hline
\end{tabular}

\subsection{Numerical Simulation of HTB of Star Wheel Shaft in WSSC}

\subsubsection{Governing Equations}

A large amount of water injected and a low temperature increase in lubricating water during the working process of WSSCs will cause the energy equation to be disregarded [24]. Water flow in HTBs is governed by the following equations.

According to the law of conservation of mass, the equation of mass conservation (i.e., continuity equation) can be written as follows:

$$
\frac{\partial \rho}{\partial t}+\frac{\partial \rho u}{\partial x}+\frac{\partial \rho v}{\partial y}+\frac{\partial \rho w}{\partial z}=0
$$

The law of conservation of momentum (i.e., Navier-Stokes equation) is shown as follows:

$$
\left\{\begin{array}{l}
\rho\left(\frac{\partial u}{\partial t}+u \frac{\partial u}{\partial x}+v \frac{\partial u}{\partial y}+w \frac{\partial u}{\partial z}\right)=\rho X-\frac{\partial p}{\partial x}+\mu\left(\frac{\partial^{2} u}{\partial x^{2}}+\frac{\partial^{2} u}{\partial y^{2}}+\frac{\partial^{2} u}{\partial z^{2}}\right) \\
\rho\left(\frac{\partial v}{\partial t}+u \frac{\partial v}{\partial x}+v \frac{\partial v}{\partial y}+w \frac{\partial v}{\partial z}\right)=\rho Y-\frac{\partial p}{\partial y}+\mu\left(\frac{\partial^{2} v}{\partial x^{2}}+\frac{\partial^{2} v}{\partial y^{2}}+\frac{\partial^{2} v}{\partial z^{2}}\right) \\
\rho\left(\frac{\partial w}{\partial t}+u \frac{\partial w}{\partial x}+v \frac{\partial w}{\partial y}+w \frac{\partial w}{\partial z}\right)=\rho Z-\frac{\partial p}{\partial z}+\mu\left(\frac{\partial^{2} w}{\partial x^{2}}+\frac{\partial^{2} w}{\partial y^{2}}+\frac{\partial^{2} w}{\partial z^{2}}\right)
\end{array}\right.
$$


where $\rho$ and $\mu$ are the density and dynamic viscosity, respectively, of water; $p$ is the water pressure in bearing clearance; $u, v$, and $w$ are the velocity components in the $x, y$, and $z$ directions, respectively; and $X, Y$, and $Z$ are the external forces per unit mass of lubricating water.

Whether a fluid is in a laminar or turbulent state can be judged using the Reynolds equation [25]:

$$
R e=\frac{\rho v l}{\mu}
$$

Note that 2300 is the critical Reynolds number of flow for liquid transition from laminar flow to turbulent flow [25]. In the current study, the Reynolds number of an HTB is expressed as follows:

$$
R e=\frac{\rho \cdot 2 \pi n R_{0} \cdot h}{60 \mu}
$$

where $\rho=10^{3} \mathrm{~kg} / \mathrm{m}^{3}$, the pitch diameter of the HTB $R_{0}=45.05 \mathrm{~mm}, \mu=10^{-3} \mathrm{~Pa} \cdot \mathrm{s}$, and the rotation speed of HTB $n=2970 \mathrm{r} / \mathrm{min}$. All Reynolds numbers obtained by substituting the water film thickness to Formula 13 are below 2300. Thus, laminar flow is used for simulation.

The following assumptions are necessary to construct the governing equations applicable to the hydrostatic water film of star wheel HTB.

(1) Given that water does not slip on bearing surfaces, the speed of the water film and that of the HTB ring is the same at their interface.

(2) Water film flowing in the bearing clearance is laminar without eddy current and turbulence. Hence, $\partial p / \partial z=0$.

(3) The volume force of water is negligible compared with the viscous force. That is, the external forces $X, Y$, and $Z$ acting on the water film are 0 .

(4) Water film flow in the bearing clearance is steady-state flow and the parameters in the flow field do not change with time, so $\partial / \partial t$ is neglected.

(5) Water pressure in the entire groove on the static ring surface is constant, and the dynamic viscosity, $\mu$, and density, $\rho$, of water are constant.

(6) The velocity component of water film in the direction of water film thickness, $w$, can be negligible. Given that $\mathrm{z}$ is substantially smaller than $\mathrm{x}$ and $\mathrm{y}, \partial^{2} / \partial x^{2}$ and are substantially smaller than $\partial^{2} / \partial z^{2}$.

On the bases of the preceding assumptions, the governing equations describing the pressure and speed of water film are obtained by simplifying and integrating as follows:

$$
\left\{\begin{aligned}
\int_{0}^{h} \rho\left(u \frac{\partial u}{\partial x}+w \frac{\partial u}{\partial y}\right) d z & =-h \frac{\partial p}{\partial x}+\int_{0}^{h} \mu\left(\frac{\partial^{2} u}{\partial z^{2}}\right) d z \\
\int_{0}^{h} \rho\left(u \frac{\partial v}{\partial x}+w \frac{\partial v}{\partial y}\right) d y & =-h \frac{\partial p}{\partial y}+\int_{0}^{h} \mu\left(\frac{\partial^{2} v}{\partial z^{2}}\right) d z \\
\int_{0}^{h}\left(\frac{\partial u}{\partial x}+\frac{\partial v}{\partial y}\right) d z & =0
\end{aligned}\right.
$$

\subsubsection{Geometric Model}

To understand the working performance of water film between the sliding surfaces of the bearing rings, the star wheel thrust bearing mainly bears a unidirectional axial gas force in WSSCs. Hence, only one unidirectional hydrostatic thrust bearing is needed. The velocity fields of water film in the proposed HTB and used in our prototype are calculated using a three-dimensional geometric model. Figure 6 shows the water film and flow in the HTB clearance (parameters are shown in Table 2). 


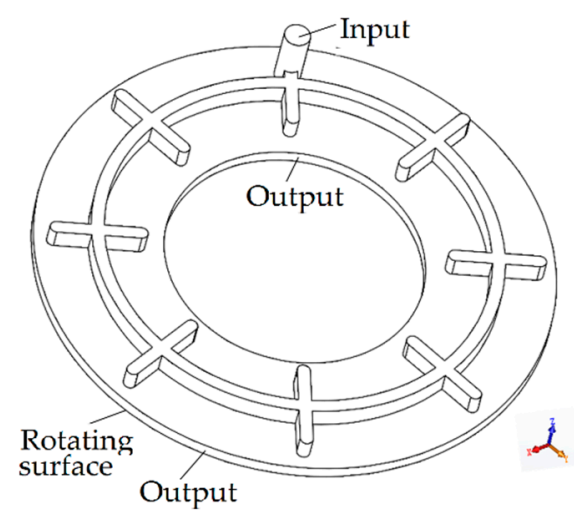

(a)

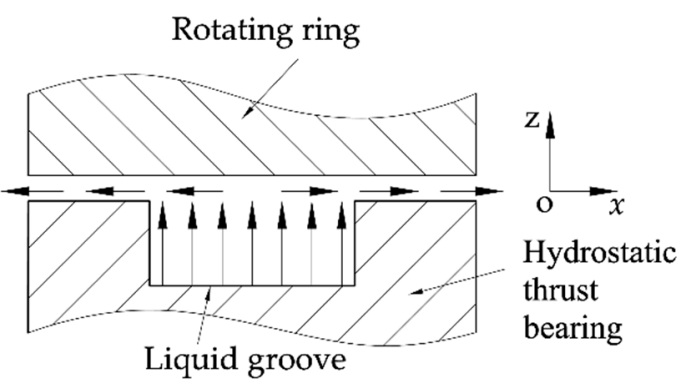

(b)

Figure 6. Geometric model: (a) water fields in the bearing clearance; (b) water flow in the HTB clearance.

\subsubsection{Simulation Process}

The model of the water film was divided with structural mesh via ICEM CFD. The mesh in the thickness direction of water film is the key point of mesh division because water film thickness is found in extremely small quantities compared with radius direction. Taking the mesh quality together with the memory allocation of the computer into account, after multiple trials until the calculation results are essentially unchanged by the number of meshes, the total number of meshes for the research subjects in this paper is 1,142,448, which is appropriate. The mesh model is shown in Figure 7.

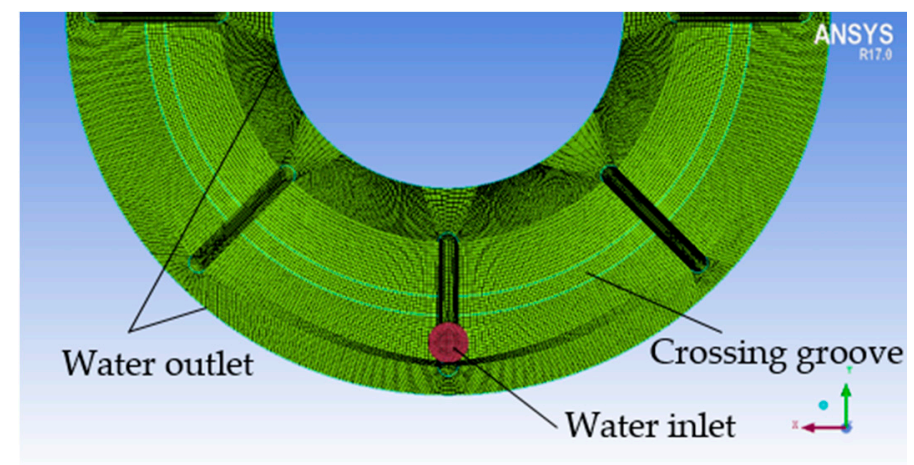

Figure 7. Mesh model of the water film.

The SIMPLE algorithm is selected as the solution method [26]. The solution considers that the fluid in the flow field inside an HTB is incompressible and the flow pattern is a three-dimensional steady flow. The boundary conditions are set as follows.

(1) Inlet boundary condition: The water pressure of the inlet is known, so the pressure inlet is adopted. The inletpressure is the water injection pressure of the WSSC.

(2) Outlet boundary condition:There are two ends in the radial direction, both of which are outlets.The water pressure of the outlet was equal to that of the external environment.

(2) Wall boundary condition:The wall in contact with the rotating ring adopted a moving wall and the speed is equal to the rotational speed of the star wheel shaft.The rest arethe stationary walls and all walls all adopt a no-slip boundary condition.

\subsection{Test Rig Description}

To explore the bearing performance of a compressor in a real working environment and verify the correctness of the model and the accuracy of the simulation results, a test rig to model the working performance of HTBs of the star wheel was developed in this research, as shown in Figure 8. 


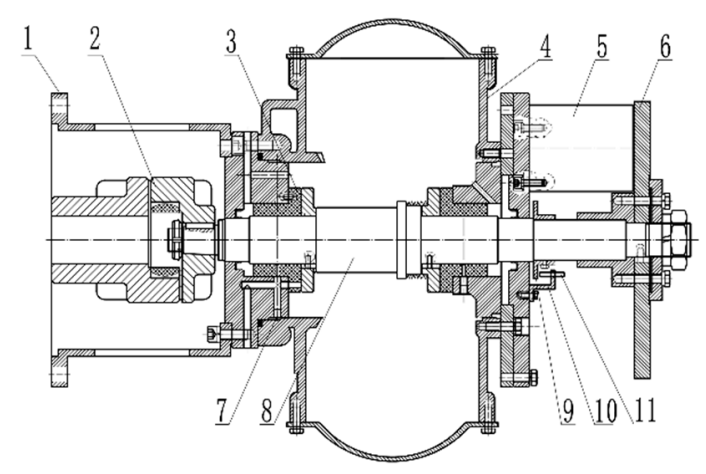

(a)



(b)

Figure 8. Test rig of water-lubricated HTB of star wheel shaft (developed by author): (a) layout of test rig arrangement; (b) test rig photo ( 1 joined cylinder, 2 coupling, 3 HTB, 4 cylinder, 5 electromagnet, 6 rotating disc, 7 injecting hole, 8 shaft, 9 disc for displacement measurement, 10 installation frame of displacement sensor,11 displacement sensor).

The injecting pressure of the water injecting pipe was adjustable and the outlet pressure of water film in the sliding clearance was atmospheric. Moreover, water injection pressure could be measured by a pressure sensor. A non-contact displacement sensor was installed on the upper base of the thrust surface of the bearing to measure the axial displacement of the star wheel shaft under the action of the pulsating force. A vortex flowmeter was also installed on the water injecting pipe to measure the water injection flowrate.

According to the force analysis of the star wheel, the axial gas force on the star wheel is an alternating load that varies with the rotation of the star wheel following a certain periodic law. In particular, pulsating load was generated by the combination of an electromagnet and control circuit to simulate the actual load of the hydrostatic thrust bearing in this research [27]. To exert a pulsating axial load (see Figure 5) on the bearing rotating ring of a star wheel, an electromagnet (5) was equipped in the test rig and placed on one side of the test rig. The electromagnetic would generate a suction force on the rotating circle plane after energizing.

Under appropriate assembly conditions, it was necessary to ensure that there was not only a certain clearance between the electromagnet and the rotating circle plane, but also that the electromagnet could produce enough suction force to the rotating circle plane under this clearance. Given that the rotating circle plane was connected with the spindle through a fixed base, the pulsating electromagnetic force was converted to the force exerted on the spindle. The rated working voltage of the electromagnet was $110 \mathrm{~V}$ DC voltage, and the maximum suction force that could be generated on the rotating circle plane under rated working conditions was $5000 \mathrm{~N}$. The suction force of the electromagnet would increase with the increase in DC voltage.

To simulate the actual force acting on the HTB of the star wheel shaft in WSSCs, electromagnetic force was calibrated with a ring pressure sensor to determine the specific relationship between the axial gas force acting on the bearing and change of input voltage. During calibration, the hydrostatic thrust bearing was replaced by an annular pressure sensor, and the clearance between the rotating circle plane and the electromagnet was adjusted to $0.3 \mathrm{~mm}$ and $0.4 \mathrm{~mm}$, respectively. The input DC voltage was adjusted to gradually increase from 0 to $110 \mathrm{~V}$, and the angle of the rotating circle plane was changed to measure the pressure corresponding to each voltage value at different rotation angles. The average value was obtained by multiple measurements to obtain the corresponding pressure relationship. 
In the experiment, it was necessary for the input voltage to be processed using the control circuit to make the voltage changes periodically according to the pulsating force. Hence, the electromagnet produced periodic suction, and the corresponding gas force was eventually simulated by adjusting the voltage.

The rotation speed of the HTB shaft driven by a motor was adjustable to test the influences of sliding speed on the lubricating state. To maintain HTB and its shaft in equilibrium, two water radial sliding bearings were installed on the shaft. Since the eddy current displacement sensor (11) used in the experiment was a non-contact measurement, an auxiliary disc (9) for measuring displacement was installed on the spindle to measure the water film thickness in the bearing clearance of the hydrostatic thrust when it was working. In addition, axial displacement of the spindle was measured using the displacement sensor during the experimental operation, which was the water film thickness. Measured data on the bearing lubrication behavior under different loads could be recorded by an NI acquisition system.

\section{Research Results and Discussion}

\subsection{Simulation and Experimental Results}

Figure 9 shows that water flows radially and circumferentially from the groove, thereby indicating that circumferential and radial velocity gradients exist in the HTB clearance.

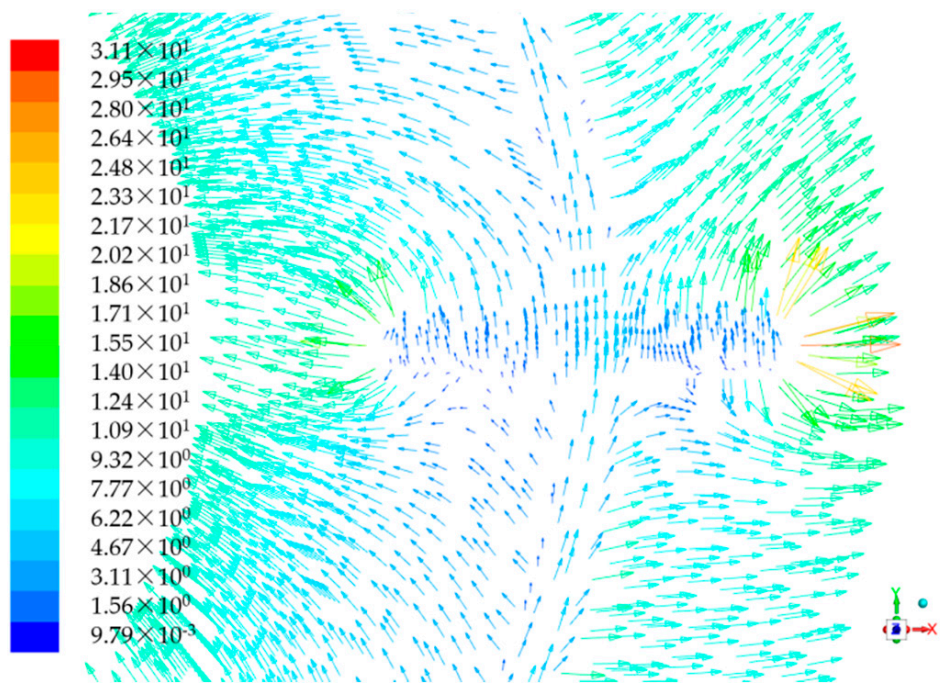

Figure 9. Water velocity distribution on the sliding surface of a star wheel shaft HTB.

Figure 10 shows simulation results of the water film pressure distribution on the static ring surface of the star wheel shaft's HTB under different axial forces of the star wheel and water injection pressures.

Evidently, when the water injection pressure is constant, water film thickness between the static and rotating bearing rings decreases gradually with an increase in their loads. When the water film reaches at least $0.1 \mathrm{~mm}$, pressure on the entire surface of the HTB ring is nearly the same. For different star wheel HTBs, a varying range of water film thickness is often expected to be between $0.03 \mathrm{~mm}$ and $0.05 \mathrm{~mm}$ to maintain reasonable clearances between star wheel pieces and compressor cylinder [24]. However, water film thickness should not be markedly below $0.015 \mathrm{~mm}$ to avoid direct contact between the two solid surfaces of a bearing. In this manner, for the numerous HTBs used in WSSCs, the excellent working stability of the star wheel in the axle is expected when the minimum and maximum values of water films are $0.015 \mathrm{~mm}$ and $0.06 \mathrm{~mm}$, respectively. 


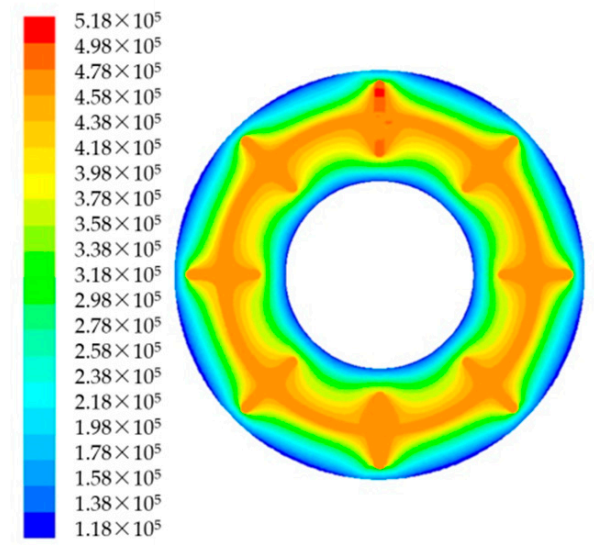

(a)
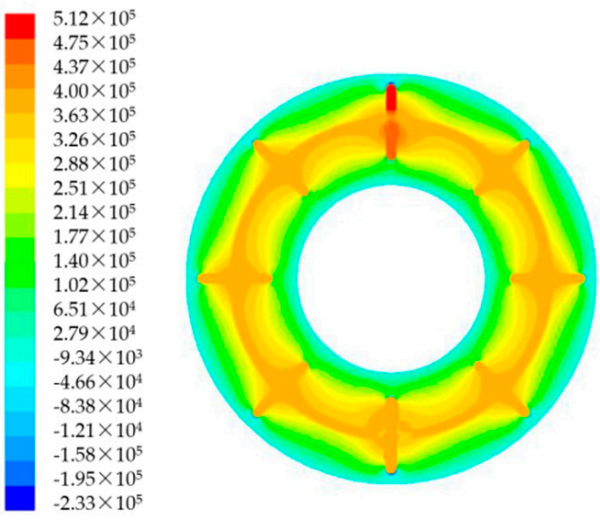

(c)
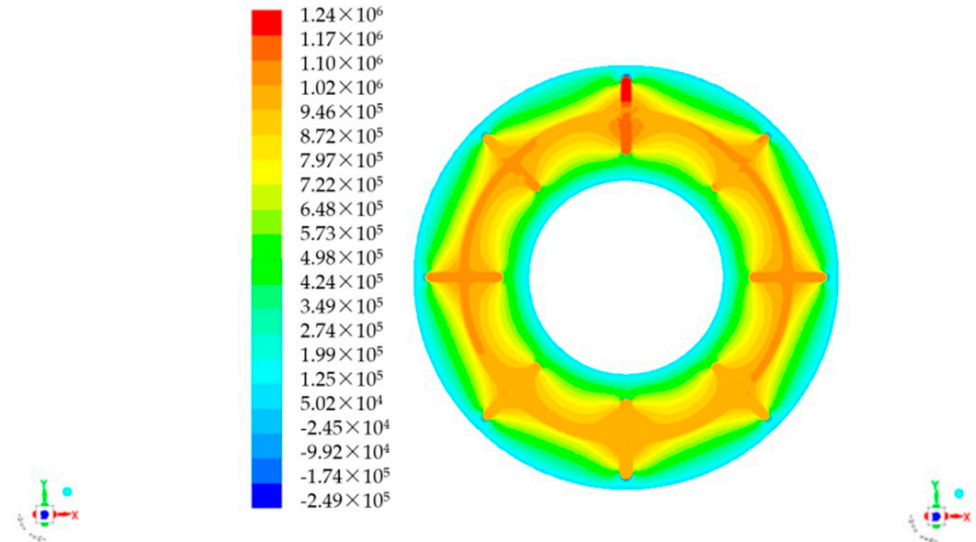

(b)

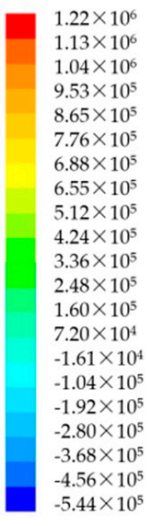

1.:-

$-5.44 \times 10^{5}$

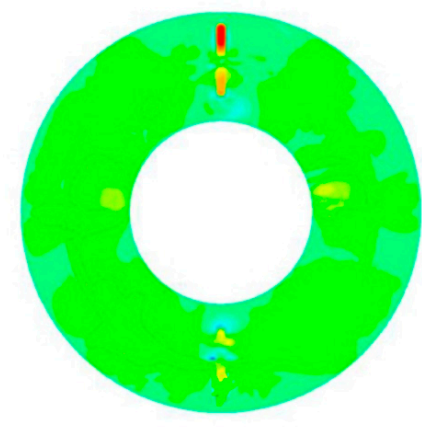

(d)

Figure 10. Pressure distribution of hydrostatic water film on static ring surface of star wheel shaft HTB: (a) $p=0.5 \mathrm{MPa}$, $\mathrm{F}_{\text {gmax }}, \mathrm{h}=0.02 \mathrm{~mm}$; (b) $p=1.2 \mathrm{MPa}, \mathrm{F}_{\text {gmax }}, \mathrm{h}=0.04 \mathrm{~mm}$; (c) $p=0.5 \mathrm{MPa}, 1 / 3 \mathrm{~F}_{\text {gmax }}, \mathrm{h}=0.07 \mathrm{~mm}$; (d) $p=1.2 \mathrm{MPa}, 1 / 3 \mathrm{~F}_{\text {gmax }}$, $\mathrm{h}=0.10 \mathrm{~mm}$.

Figure 11 depicts a sectional view of 3D pressure distribution of the water-lubricated HTB of a star wheel shaft in a WSSC on a sliding surface.

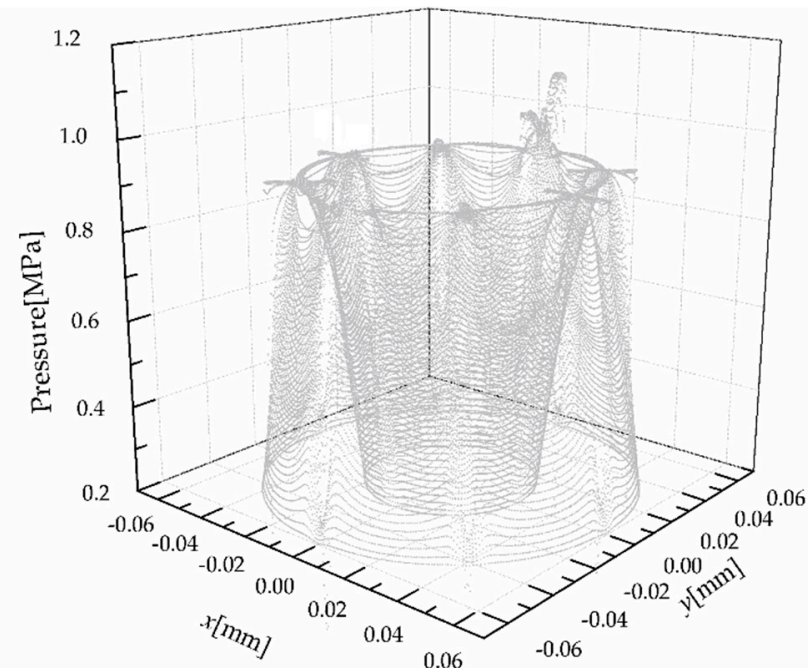

Figure 11. 3D pressure distribution in the lubrication film of the HTB. 
Figure 11 shows the intuitive trend of pressure distribution that pressure in the water groove is the highest and gradually decreases in the radial direction of the inner and outer edge of the bearing.

Under the dynamic periodic load simulating the real force of the star wheel, Figure 12 shows the change of the liquid film thickness of the bearing.

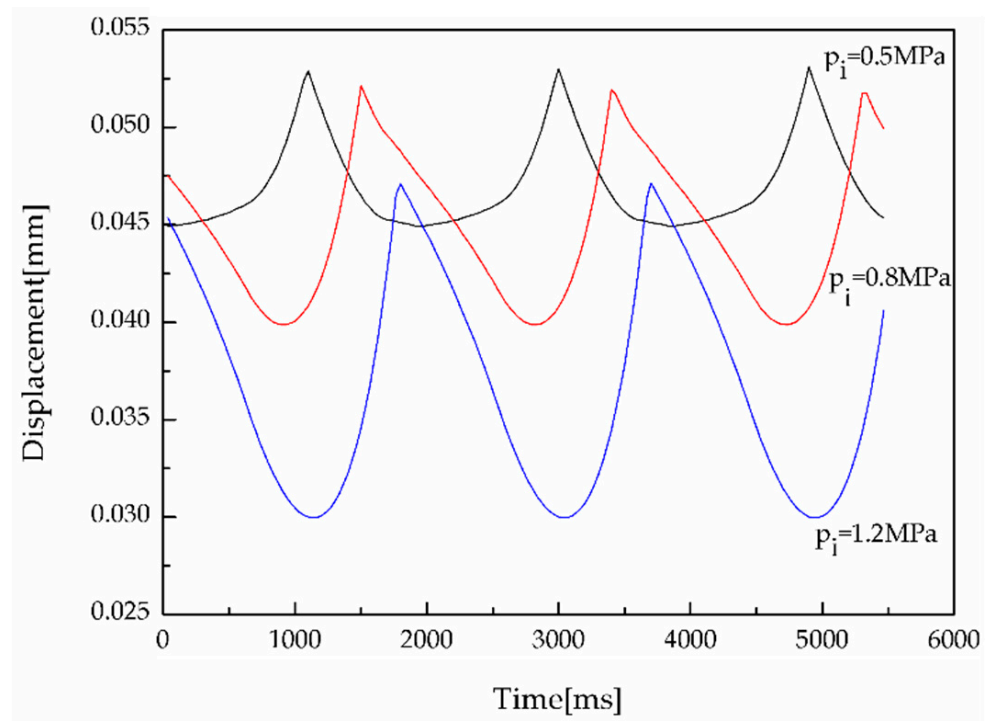

Figure 12. Displacement under dynamic load.

The displacement in the figure is the water film thickness in the bearing clearance. It is seen that although the exerted electromagnet force fluctuates substantially, the measured water lubricating the film in the bearing sliding clearance is nearly constant. The high frequency of the exerted load can also obtain steady water-lubricating film thickness.

To verify the performance of the hydrostatic thrust bearing designed in this paper, some comparisons are made as follows.

Figure 13 shows the comparison of the bearing capacity. On the basis of the same hydrostatic chamber area, the lubrication characteristics of the hydrostatic bearing with the traditional annular groove are compared with those of the hydrostatic bearing with the groove described in this research under the same depth of hydrostatic chamber. For cases with three water injection pressures, Figure 13a shows a comparison of the variation of bearing capacity with the water film thickness of HTBs with the traditional annular groove and a crossing groove. Figure $13 \mathrm{~b}$ represents a comparison of the experimental results with simulated results of the relationship between the bearing capacity of the HTB of the star wheel shaft and the water film thickness under three different water injection pressures.

The calculation method for the bearing capacity of an HTB with an annular groove in this paper is the same as that in the literature $[13,28]$; the calculated results in this paper are basically consistent with their trend and value ratio. Evidently, the bearing capacity of HTB with an annular groove is larger than that of the crossing groove. The difference increases with an increase in the water injection pressure. The bearing capacity of an HTB is the product of the effective bearing area and pressure in the groove. Given the effective bearing areas of the two types of HTBs are constant, in the annular groove, it is higher than that of the crossing groove, and the difference increases with an increase in the water injection pressure. 


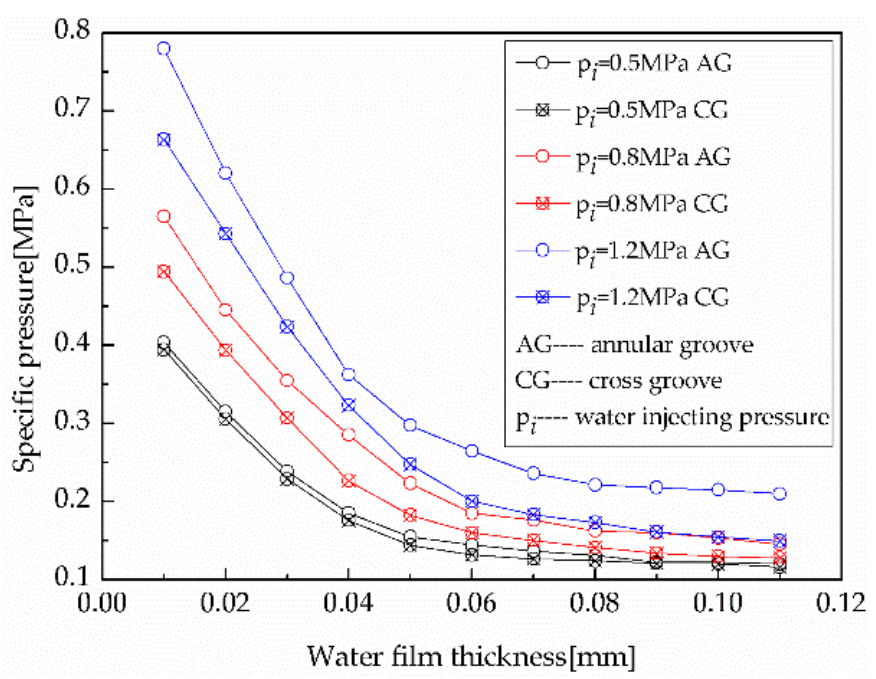

(a)

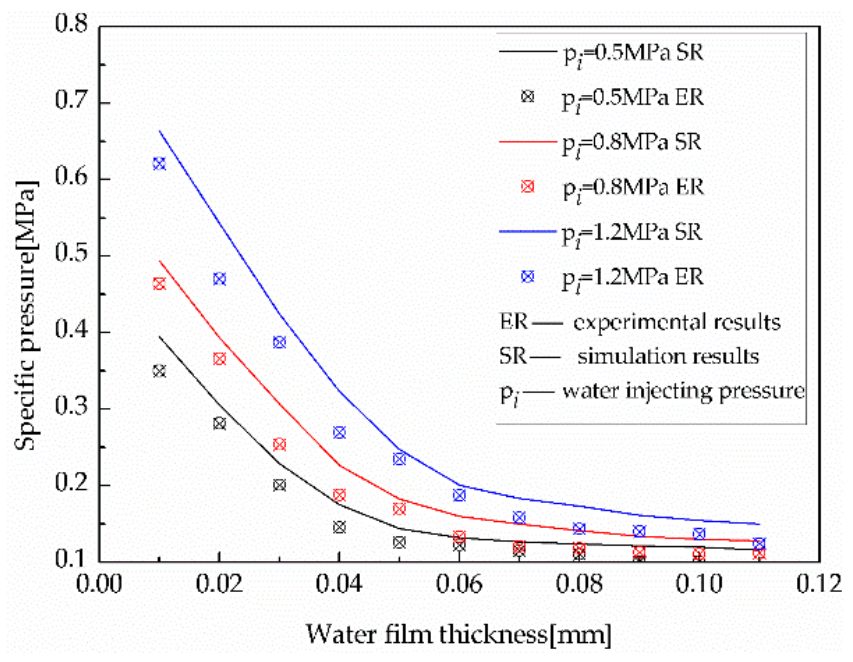

(b)

Figure 13. Comparison of the bearing capacity for (a) annular groove vs. crossing groove (simulated results), (b) crossing groove (simulated results vs. experimental results).

Note that the bearing capacity of an HTB decreases rapidly with an increase in the thickness of the water film in the range of $0-0.06 \mathrm{~mm}$ of water film thickness. When water film thickness becomes thicker than $0.05-0.06 \mathrm{~mm}$, bearing capacity is relatively small and even. In addition, high water injection pressure can remarkably increase bearing capacity. However, the maximum water injection pressure often is the discharge pressure of WSSCs. This discharge pressure is sufficient to form a thick water film and to support a star wheel. Furthermore, the working loads of a star wheel in WSSCs have the parameters listed in Table 1 and labeled in Figure 13. Under the working loads, sufficient thick water film can be formed. By contrast, the relations between loads and lubricating films of the simulation and experimental results have the same changing trend.

However, the simulated and experimental data points have some slight differences for the same axial force and same injecting pressure. The error may come from some deflections arising from the rotating shaft and bearing ring in the rig. In the numerical simulation, the static and rotating rings of the bearing are supposed to be parallel to each other. Moreover, errors may come from the standard testing of the water film measurement in the rig.

Comparison is drawn in Figure 14a on the variation of the water supply with the water film thickness of two types of HTBs. Figure 14b shows the relationship between water supply and water film thickness of HTBs under three different water injection pressures. The experimental and simulated results are likewise listed.

Figure 14 shows that the water supply of an HTB with the crossing groove is smaller than that of the annular groove. Circumferential and radial flows are present owing to the existence of radial short channels, as shown in Figure 8. The existence of a radial short channel also increases the flow channel of the lubricant water, thereby reducing the amount of water. The water supply difference between the two types of HTBs is extremely small when the water film thickness is small. The difference gradually increases with an increase in water film thickness, which is due to the cubic correlation between water supply and bearing clearance according to the empirical formula. 


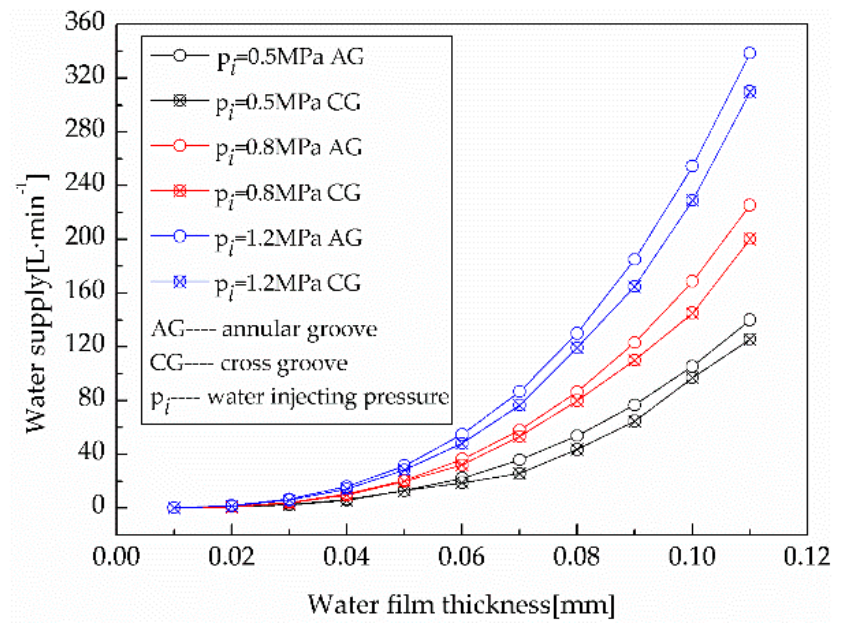

(a)

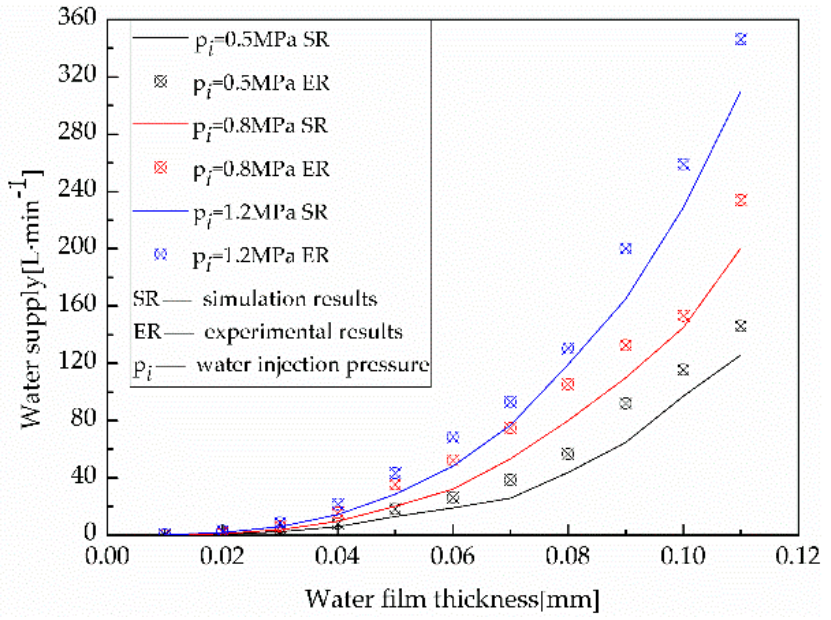

(b)

Figure 14. Comparison of the water supply for (a) annular groove vs. crossing groove (simulated results), (b) crossing groove (simulated results vs. experimental results).

Compared with the simulation results, the experimental and simulation values describe the same trend of water flowrate change in the sliding clearance of an HTB. The water flowrate measured by the experiment is larger than that of the simulation. The possible reason for errors is that the numerical calculation model is based on the ideal assumption that water film thickness is uniform. The experimental test focuses on engineering practice, which may be caused by a machining error, assembly error of bearing working surface, or tilt between working faces of HTB, resulting in uneven actual water film thickness. Thereafter, water supply increases.

\subsection{Discussion}

One of the major aims of this research is to control the hydrostatic water film thickness in a proper range because there is extremely limited assembly space for WSSCs. The results indicate that as water injection pressure increases, the bearing capacity of the HTB increases. The supply flowrate increases with an increase in water film thickness and water injection pressure. According to the hypothesis (presented at the beginning of the third section), this study only involves the simulation of steady lubrication states under different constant force loads acting on an HTB. However, force loading, hydrostatic water film and film pressure, among others, are constantly changing in the practical operation of WSSCs. The pulsation frequency of their loading force is approximately $200-400 \mathrm{~Hz}$. To describe this unsteady lubrication state, an evaluating method of maximum and minimum values, which is well-known as the "squeeze effect" in a narrow clearance flow of a fluid, is used. When the load on an HTB increases, the hydrostatic lubricating film, $h$, becomes thinner. This "getting thinner" has an effect that is a reaction against getting thinner. However, when the load on HTB decreases, the hydrostatic lubricating film, h, becomes thicker. Accordingly, this "getting thicker" has an effect that is a reaction against getting thicker. A steady hydrostatic water film, $\mathrm{h}_{\min }$, under a constant maximum load, $\mathrm{W}_{\max }$, must be the limitation of pulsating hydrostatic water film under the changing load that does not exceed $\mathrm{W}_{\max }$. Similarly, a steady hydrostatic water film, $\mathrm{h}_{\max }$, under constant minimum load, $\mathrm{W}_{\mathrm{min}}$, must be the limitation of a pulsating hydrostatic water film under the changing load, which is not as low as $W_{\min }$.

Both simulation and experimental results show that the newly proposed structure of the HTB can meet the requirements of loading pulsating gas force within the allowable clearance range of the WSSC. The comparison of the water consumption of the two types of HTB shows that the new structure is more water-efficient. For star wheel bearings, it is necessary to consume less water while maintaining its stability because the liquid supply 
of the single-screw compressor is limited. All the above means that the new modification is suitable for the star wheel shaft of WSSCs. The steady-state hydrostatic lubrication simulating model developed in this study can be used to determine HTB sizes and its water injection pressures for WSSCs. When a bearing designed in this manner is implemented, its water lubrication films will be in the range of $h_{\min }$ to $h_{\max }$.

Accordingly, there is no sudden change in the thickness of the water film because the force changes continuously and periodically when the discharge pressure of the WSSC remains unchanged. In experiment, all data were measured and collected after the system ran stably, and the water film thickness in the bearing clearance would fluctuate at the same frequency as the force fluctuated. The deflection of the component caused the oscillation in the direction of water film thickness, but its frequency was different from the fluctuation frequency of force. During data processing, the signal data with the same frequency of components deflection were isolated from the original data by FFT in Mathcad software. Finally, data regarding the water film thickness were obtained by IFFT.

In the numerical simulation, it was assumed that water did not slip on the bearing surface. However, in the experiment, due to the low viscosity of water, the water velocity near the surface of the HTB ring may be different from the bearing speed.

\section{Conclusions}

On the bases of the simulation and experimental investigations of the HTB of the star wheel shaft in a WSSC, remarkable achievements were made, and the following main conclusions can be drawn.

(1) A new structure of a water-lubricated HTB of star wheels was developed, in which an annular groove with numerous crossing short grooves was proposed.

(2) The lubrication characteristics were compared between HTBs with two types of grooves. The results show that the bearing capacity of an HTB with an annular groove is larger than that of an HTB with a crossing groove. However, water supply is also increased. The HTB with a crossing groove is more suitable for WSSCs because of the lower water consumption on the premise of equivalent bearing capacity.

(3) A distinctive HTB test rig with an electromagnet loading system was designed and constructed to test and verify the new design and calculation results of a star wheel HTB's lubricating state in WSSCs. There was good agreement between the experimental results and simulation results.

(4) A proper range of hydrostatic lubrication film should be limited in the range between $0.015 \mathrm{~mm}$ and $0.06 \mathrm{~mm}$ for the star wheels of WSSCs. A new structure of a star wheel HTB proposed in this research can offer reasonable bearing capacity in this limited water film thickness, even if the gas load acting on HTB varies substantially.

In the experiment, only axial force was applied to the HTB, and the radial bearing just bore the weight of the shaft itself. Our analysis neglects the radial displacement. We readily admit that a short test may not fully reflect the performance of the HTB in a WSSC. The results of this research may be useful for design of an HTB for WSSCs with large displacement and a high compression ratio. An important direction for further work might be to study the performance of the HTB with crossing groove in WSSCs during long-term operation. Additionally, a further experiment should be conducted with a more sophisticated measuring system with axial and radial displacement.

Author Contributions: The individual contributions are as follows: methodology, W.Z.; software, J.X.; validation, W.Z., C.P. and J.X.; investigation, J.X.; data curation, C.P.; writing-original draft preparation, J.X.; writing-review and editing, Q.F.; supervision, C.Z. All authors have read and agreed to the published version of the manuscript.

Funding: This research received no external funding.

Conflicts of Interest: The authors declare no conflict of interest. 


\section{References}

1. Li, T.; Huang, R.; Feng, Q.-K.; Wu, W.-F.; Liu, F.-L.; Yu, X.-L. Hydrodynamic lubricating characteristics of water flooded single screw compressors based on two types of meshing pair profile. Proc. Inst. Mech. Eng. Part J J. Eng. Tribol. 2016, 230, 1092-1106. [CrossRef]

2. Haselden, G. Potential of the single-screw compressor. Int. J. Refrig. 1985, 8, 215-220. [CrossRef]

3. Hirai, T.; Noda, S.; Sagara, Y.; Tsuizi, K. Performance analysis of OIF single screw compressor. In Proceedings of the 8th International Compressor Engineering Conference at Purdue, West Lafayette, IN, USA, 4-7 August 1986; pp. 119-134.

4. Wu, W.; Feng, Q. A Multicolumn Envelope Meshing Pair for Single Screw Compressors. J. Mech. Des. 2009, 131, 074505. [CrossRef]

5. Ojile, J.O.; Teixeira, J.A.; Carmody, C. Mechanical Seal Failure Analysis. Tribol. Trans. 2010, 53, 630-635. [CrossRef]

6. Song, Y.; Zeng, S.; Ma, J.; Hou, J. Failure Analysis of Graphite Stationary Ring Utilized in One Type of Mechanical Seal. Eng. Fail. Anal. 2019, 108, 104259. [CrossRef]

7. Qiu, B.Y.; Lin, H.J.; Yuan, S.Q. Guide bearing probability load theory of large vertical pump. Mech. Mach. Theory 2007, 42, 1199-1209.

8. He, Y.C.; Liu, Z.L.; Wu, Z.X. Numerical analysis of lubricating property of submersible pump water-lubricated trust bearing. Lubr. Eng. 2010, 35, 59-62.

9. Heidrich, F.L. Water flooded single screw (SSP) compressor technology. In Proceedings of the 13th International Compressor Engineering Conference at Purdue, West Lafayette, IN, USA, 23-26 July 1996; pp. 145-150.

10. Li, T.; Wang, Y.; Mao, X.; Chen, D.; Huang, R.; Feng, Q. Development and Experimental Study of the First Stage in a Two-Stage Water-Flooded Single-Screw Compressor Unit for Polyethylene Terephthalate Bottle Blowing System. Energies 2020, 13, 4232 [CrossRef]

11. Zhang, Z.; Wu, W. Numerical investigation of thermal deformation of meshing pairs in single screw compressor. Appl. Therm. Eng. 2021, 188, 116614. [CrossRef]

12. Rohmer, M.; Andres, L.S.; Wilkinson, S.M. Static Load Performance of a Water-Lubricated Hydrostatic Thrust Bearing. J. Eng. Gas Turbines Power 2018, 140, 062401. [CrossRef]

13. Wang, Y.Z.; Jiang, D.; Yin, Z.W.; Gao, G.Y.; Zhang, X.L. Load capacity analysis of water-lubricated hydrostatic thrust bearing based on CFD. J. Donghua Univ. Nat. Sci. 2015, 41, 428-447.

14. Liu, Q. Research on the Load Carrying Capacity of Large Water-Lubricated Thrust Bearing and the Optimization of Thrust Pad Profile. Ph.D. Thesis, North University of China, Taiyuan, China, 2013.

15. Andrés, L.S.; Phillips, S.; Childs, D. A Water-Lubricated Hybrid Thrust Bearing: Measurements and Predictions of Static Load Performance. J. Eng. Gas Turbines Power 2016, 139, 022506. [CrossRef]

16. Zhang, H.; Zheng, W.; Li, F. Simulation Design and Numerical Analysis of Bearing Capacity of Water Lubricated Thrust Bearing. IOP Conf. Ser. Earth Environ. Sci. 2020, 446, 052081. [CrossRef]

17. Sternlicht, B.; Elwell, R.C. Theoretical and Experimental Analysis of Hydrostatic Thrust Bearings. J. Basic Eng. 1960, 82, 505-512.

18. Rowe, W.B. Hydrostatic and hybrid bearing design. Tribol. Int. 1984, 17, 353. [CrossRef]

19. Chen, Y.S. Principle and Design of Hydrostatic Bearing; National Defense Industry Press: Beijing, China, 1980.

20. Ding, Z.Q. Design of Hydrostatic Bearing; Shanghai Science and Technology Press: Shanghai, China, 1986.

21. Tian, Z.X. Research on the Characteristics and Their Affecting Factors of the Hydrostatic Thrust Bearing. Ph.D. Thesis, Huazhong University of Science and Technology, Wuhan, China, 2018.

22. Zhong, H.; Zhang, G.K. Manual for Design and Application of Hydrostatic and Hybrid Bearings; Publishing House of Electronics Industry: Beijing, China, 2007; pp. 44-45.

23. Peng, C.; Wu, W.; Zhang, Z.; Xie, J.; Feng, Q.; He, Z. Dynamic characteristics improvement of the single screw compressor with odd-grooves screw rotor. Int. J. Refrig. Online 2021. [CrossRef]

24. Yu, Y.Z. Technical Manual of Positive Displacement Compressor; China Machine Press: Beijing, China, 2005.

25. Zhou, G.J.; Yan, Z.Y.; Xu, S.X.; Zhang, K.B. Fluid Mechanics; Higher Education Press: Beijing, China, 2000.

26. Pletcher, R.H.; Tanyhill, J.C.; Anderson, D.A. Computational Fluid Mechanics and Heat Transfer; World Book Inc.: Beijing, China, 2021.

27. Chen, H.M. Research on Hydraulic Loading System of an Aviation Bearing Test-Bed. Master's Thesis, Central South University, Changsha, China, 2010.

28. Wang, Y.; Wang, L.J.; Wang, X.Y. Design of hydrostatic thrust bearing and simulation analysis by Fluent. Mach. Des. Manuf. 2017, 9, 220-224. 